\title{
Nitrogen removal in a Sequencing Batch Biofilm Reactor: effect of carbon availability and intermittent aeration
}

\author{
M. Vieira, A.G. Brito and R. Nogueira* \\ IBB-Institute for Biotechnology and Bioengineering, \\ Centre of Biological Engineering, \\ University of Minho, \\ Campus de Gualtar, 4710-057 Braga, Portugal \\ E-mail: mvieira@deb.uminho.pt \\ E-mail: agbrito@deb.uminho.pt \\ E-mail: regina@deb.uminho.pt \\ ${ }^{*}$ Corresponding author
}

\begin{abstract}
This study aimed to investigate the effects of carbon availability and intermittent aeration on nitrogen removal in a Sequencing Batch Biofilm Reactor (SBBR). The percentage of nitrogen removal in the SBBRs operating with dump fill and slow fill with optimum intermittent aeration was quite similar, $75.7 \%$ and $69.2 \%$, respectively, indicating that intermittent aeration allowed a considerable energy saving without compromising significantly nitrogen removal. Accumulation of storage polymers by heterotrophic bacteria was only observed in the dump fill mode of operation. FISH analyses of the biofilm indicated that ammonia-oxidisers belonged to the beta-subclass Proteobacteria and nitrite-oxidisers were affiliated with the genus Nitrospira.
\end{abstract}

Keywords: SBBR; sequencing batch biofilm reactor; nitrification; denitrification; intermittent aeration.

Reference to this paper should be made as follows: Vieira, M., Brito, A.G. and Nogueira, R. (2009) 'Nitrogen removal in a Sequencing Batch Biofilm Reactor: effect of carbon availability and intermittent aeration', World Review of Science, Technology and Sustainable Development, Vol. 6, Nos. 2/3/4, pp.173-185.

Biographical notes: Madalena Vieira manages the laboratory facilities of the Department of Biological Engineering, University of Minho. She holds a Masters Degree in Environmental Technology and is graduated in Chemical Engineering. Her research interests include wastewater treatment using biofilm reactors, sequencing batch reactors and instrumentation.

António G. Brito is an Assistant Professor at the Department of Biological Engineering, University of Minho, and Researcher at the Institute of Biotechnology and Bioengineering. He holds a $\mathrm{PhD}$ in Biological and Chemical Engineering and is graduated in Environmental Engineering. Actually, he is the President of Environmental Engineering College of the Portuguese Institution of Engineers as well as of the Portuguese Society for Environmental Simulation and Risk Assessment and member of the 
National Water Council. His research interests are focused on biofilm processes, water management and wastewater/wastes biovalorisation.

Regina Nogueira is an Assistant Professor at the Department of Biological Engineering, University of Minho, and researcher at the Institute of Biotechnology and Bioengineering. She holds a $\mathrm{PhD}$ in Chemical and Biological Engineering and is graduated in Biological Engineering. Her research focuses on biofilm processes in engineered and natural ecosystems. The specific areas of her biofilm interests include the removal of nitrogen compounds, the evaluation and modelling of microbial population dynamics for the removal of natural organic matter and for bioenergy production.

\section{Introduction}

Eutrophication is a condition in an aquatic ecosystem where high nutrient concentrations stimulate blooms of algae (e.g., phytoplankton). Human activities can greatly accelerate eutrophication by increasing the rate at which nutrients and organic substances enter aquatic ecosystems from their surrounding watersheds. These nutrients can come from urban sources like wastewater treatment facilities and runoff from fertilised lawns. The resulting need to enhance nitrogen removal in wastewater treatment due to stricter nitrogen and phosphorus discharge limits renewed the interest of the scientific community on Sequencing Batch Reactor (SBR) technology research and development (Christensson and Welander, 2004).

The SBR process is a sequential suspended growth (activated sludge) process in which all major phases occur in the same tank in sequential order, namely, fill, react (aeration/mixing), settle, draw and idle (Mace and Mata-Alvarez, 2002). The possibility to change the length of each phase individually provides considerable flexibility to the process (Wilderer et al., 2001). The SBR can be combined with biofilm growth on the surface of a support material, originating the Sequencing Batch Biofilm Reactor (SBBR). In SBBR systems, high concentrations of biomass can be maintained independently of the sedimentation characteristics of the biological aggregates and the hydraulic retention time of the reactor (Nicolella et al., 2000). SBBR reactors are particularly suitable when the required microbial population grows very slowly or when the biomass yield is low (Tam et al., 2004).

Biological nitrogen removal in SBRs can be achieved by sequential nitrification and denitrification processes under alternating aerobic-anoxic conditions (Qin and Liu, 2006). The length of the aerobic and anoxic phases determines the amount of nitrogen removed (Rodrigues et al., 2001; Brito et al., 2007). On the one hand, a long aeration phase favours the nitrification process, but on the other hand it wastes organic carbon in heterotrophic growth that could be used for denitrification. Several strategies of SBR operation have been reported in literature to overcome this problem, namely: 
- addition of external carbon source - increases the cost and complexity of wastewater treatment and is not desirable for on-site applications (Foglar and Briski, 2003)

- implementation of high frequency intermittent aeration in combination with intermittent-feed carried out only under anoxic conditions - allows a more efficient use of the organic carbon content present in the wastewater for denitrification (Batistoni et al., 2003; Puig et al., 2004; Luostarinen et al., 2006)

- online monitoring of ORP, $\mathrm{pH}$ and $\mathrm{DO}$ - controls the length of the aerobic and anoxic phases (Andreottola et al., 2001; Kishida et al., 2004).

Another possibility to achieve biological nitrogen removal in SBRs is to perform Simultaneous Nitrification and Denitrification (SND). SND implies that nitrification and denitrification occurs concurrently in the same reactor under identical overall operating conditions. The explanation for the phenomena is that SND occurs as a consequence of oxygen concentration gradients within microbial flocs or biofilms due to diffusional limitations (Third et al., 2003). That is nitrifiers exist in regions with high oxygen concentrations, whereas the denitrifiers will preferentially be active in zones with very low oxygen concentrations. As ammonium oxidation is a relatively slow process, SND requires a slowly degradable carbon substrate for denitrification. Microbial communities when subjected to feast-famine conditions over time store substrates as internal polymers (storage response), which is the fastest adaptation to the changing environment. Poly-Beta-Hydroxybutyrate (PHB) is the most abundant storage polymer in bacteria present in activated sludge processes. This internal carbon source is degraded much slower than soluble substrate and can be used in the denitrification when no external substrate is available (Beun et al., 2002).

The SBBR process, as opposed to the SBR process, is still poorly documented in literature, in particular the storage phenomena in the biofilm (Nogueira et al., 2008). Nevertheless, this knowledge is certainly needed for the optimisation of SBBRs operating strategies for nitrogen removal. The aim of this study was to investigate the effects of organic carbon availability and of intermittent aeration in a SBBR performing nitrogen removal.

\section{Materials and methods}

\subsection{Experimental set-up}

A Sequencing Batch Biofilm Reactor (SBBR), as depicted in Figure 1, with a volume of $28 \mathrm{~L}$ was operated with a constant cycle time of $300 \mathrm{~min}$, a volume exchange ratio (volume exchanged per cycle divided by reactor volume) of $0.36 \mathrm{~L} \cdot \mathrm{L}^{-1}$ and a resulting hydraulic retention time (HRT) of $9.2 \mathrm{~h}$.

Two distinct strategies of filling up the SBBR were tested, namely dump fill and slow fill. The length of the individual operating phases in the dump fill strategy was: $115 \mathrm{~min}$ mixed fill, $165 \mathrm{~min}$ react (continuously aerated) and $20 \mathrm{~min}$ draw. The duration of the individual operating phases in the slow fill strategy was: $300 \mathrm{~min}$ mixed fill, $280 \mathrm{~min}$ react (intermittent aerated/non-aerated periods) and $20 \mathrm{~min}$ draw. The operating conditions of the SBBR for dump fill and slow fill are summarised in Table 1. 
Figure 1 Experimental set-up

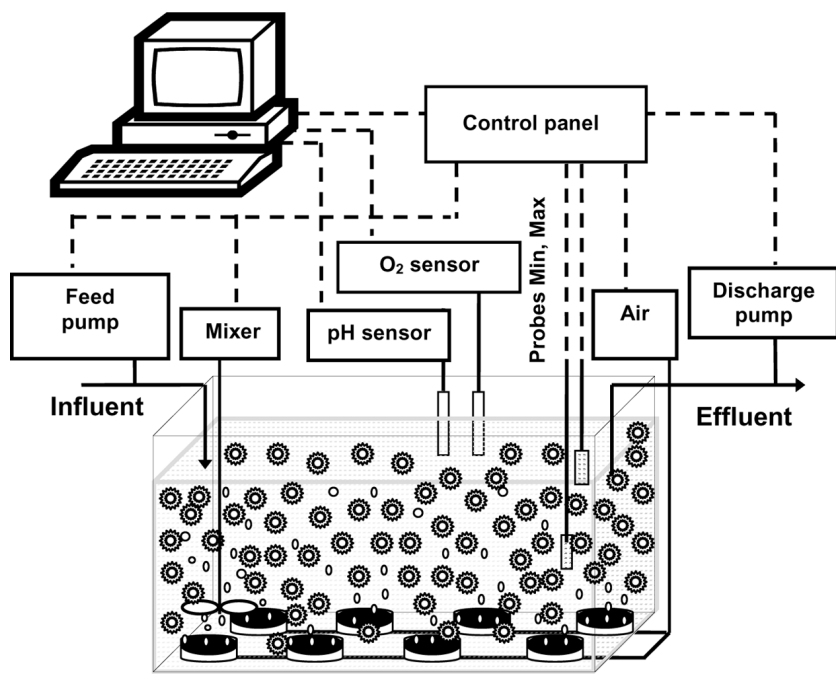

Table $1 \quad$ SBBR operating conditions

\begin{tabular}{lcccc}
\hline Fill mode & $\begin{array}{c}\text { Aerated time } \\
(\mathrm{min})\end{array}$ & $\begin{array}{c}\text { Non-aerated time } \\
(\mathrm{min})\end{array}$ & $\begin{array}{c}\text { Aerated period } \\
(\mathrm{min})\end{array}$ & $\begin{array}{c}\text { Non-aerated period } \\
(\mathrm{min})\end{array}$ \\
\hline Dump fill & 165 & 115 & 165 & 115 \\
Slow fill & 140 & 140 & 10 & 10 \\
Slow fill & 60 & 220 & 6 & 22 \\
Slow fill & 50 & 230 & 5 & 23 \\
Slow fill & 20 & 260 & 2 & 26 \\
\hline
\end{tabular}

Experiments were carried out in the slow fill mode of operation with several total aeration times, namely $20 \mathrm{~min}, 50 \mathrm{~min}$, $60 \mathrm{~min}$ and $140 \mathrm{~min}$. Short aerated/non-aerated periods were performed in the slow fill mode of operation during the react phase instead of a unique aerated period, as in the dump fill mode. Acetate and ammonium loads were identical in both modes of operation, respectively, $1.15 \mathrm{~kg} \cdot \mathrm{m}^{-3} \cdot \mathrm{d}^{-1}$ and $0.14 \mathrm{~kg} \cdot \mathrm{m}^{-3} \cdot \mathrm{d}^{-1}$. During the aerated periods, airflow of $27 \mathrm{~L} \mathrm{~min}^{-1}$ was applied through membrane diffusers, causing the reactor contents including the support bed to circulate. The SBBR was operated at $23 \pm 1^{\circ} \mathrm{C}$ and $\mathrm{pH} 7.5 \pm 0.1$. A mixer was placed in the SBBR near the feed inlet point to homogenise the reactor's content. The SBBR was completely automated, with feed and discharge pumps, mixer, airflow valve and phase lengths controlled by National Instruments instrumentation control software LabVIEW $^{\circledR}$. The feed and discharge pumps were actuated by two level probes namely maximum and minimum. Dissolved oxygen concentration (YSI 5000) and pH (WTW pH526) were monitored online using the control software LabVIEW ${ }^{\circledR}$.

The biofilm was formed on a new type of plastic support (Figure 2) developed by University of Minho (Portugal). The support is made of polyethylene and has $10 \mathrm{~mm}$ height and $30 \mathrm{~mm}$ diameter and a resulting specific surface of $407 \mathrm{~m}^{2} \cdot \mathrm{m}^{3}$. The reactor filling-fraction (volume occupied by the support divided by reactor's total volume) was $47 \%$. 
Figure 2 Support

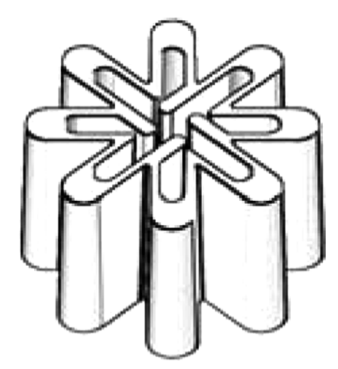

\subsection{Synthetic media composition}

The composition of the synthetic media was $643 \mathrm{mg} \cdot \mathrm{L}^{-1} \mathrm{NaCH}_{3} \mathrm{COO} \cdot 3 \mathrm{H}_{2} \mathrm{O}, 134 \mathrm{mg} \cdot \mathrm{L}^{-1}$ $\mathrm{NH}_{4} \mathrm{Cl}, 210 \mathrm{mg} \cdot \mathrm{L}^{-1} \quad \mathrm{NaHCO}_{3}, 49 \mathrm{mg} \cdot \mathrm{L}^{-1} \quad \mathrm{KH}_{2} \mathrm{PO}_{4}$ and $1 \mathrm{~mL} \cdot \mathrm{L}^{-1}$ of trace solution (Vishniac and Santer, 1957). The media has $\mathrm{C} / \mathrm{N}$ ratio of $3.24 \mathrm{~g} \cdot \mathrm{g}^{-1}$, which is similar to the one of domestic sewage.

\subsection{Sampling and analytical procedures}

Ammonium, nitrite and nitrate were measured spectrophotometrically in liquid samples previously filtered with $0.22 \mu \mathrm{m}$ membrane filters according to Standard Methods (APHA, 1995). Acetate was analysed in liquid samples previously filtered with $0.22 \mu \mathrm{m}$ membrane filters using an HPLC system (KNAUER) with UV-detection at $210 \mathrm{~nm}$ and an organic acid column (PL Hi-Plex H $8 \mu \mathrm{m}, 100 \mathrm{~mm} 7.7 \mathrm{~mm}$, Polymer Laboratories) at $65^{\circ} \mathrm{C}$. The mobile phase consisted of an aqueous $\mathrm{H}_{2} \mathrm{SO}_{4}$ solution $\left(2 \mathrm{mmol} \cdot \mathrm{L}^{-1}\right)$ at a flow rate of $0.7 \mathrm{~mL} \cdot \mathrm{min}^{-1}$.

Biofilm and suspended biomass dry weight (determined as total suspended solids) were measured according to Standard Methods (APHA, 1995) using $47 \mathrm{~mm}$ fibre glass membrane filters (Whatman GF/C). Prior to this analysis, the biofilm was detached from the support material by mechanical means (vortex).

Distribution of PHB within the biomass (both suspended and biofilm) was detected by dyeing of samples with Nile blue in accordance with Rees et al. (1992). Nile blue dye has a specific affinity to PHB and displays a strong shining orange colour when observed under an epifluorescence microscope.

Poly-Beta-Hydroxybutyrate (PHB) and Poly-Beta-Hydroxyvalerate (PHV) content of suspended biomass and biofilm were measured by Gas Chromatography (GC) using the method developed by Smolders et al. (1994). Biomass samples were previously fixed in a $2 \%(\mathrm{v} / \mathrm{v})$ formaldehyde solution and kept at $4^{\circ} \mathrm{C}$.

In situ hybridisation of cells in the biofilm was performed with fluorescently labelled rRNA-targeted oligonucleotide probes according to Manz et al. (1992). Samples of biofilm were fixed with a $4 \%$ paraformaldehyde solution, removed mechanically from the support, homogenised and kept at $4^{\circ} \mathrm{C}$. First, the samples were hybridised with a EUB338 probe set (EUB338, EUB338-II, EUB338-III) designed to target almost all bacteria (Daims et al., 2001). Then, within this domain, the beta- and gamma-subclasses of Proteobacteria were labelled with the respective group-specific probes Bet $42 \mathrm{a}$ and Gam42a (Manz et al., 1992). Within the beta-subclasses, in turn, the ammonia-oxidising bacteria were detected using the Nso1225 and Nso190 probes, which are specific for all 
ammonia-oxidisers in the beta-subclass Proteobacteria (Mobarry et al., 1996). The following probes were used to detect nitrite-oxidising bacteria:

- Nit3, which is complementary to a sequence region of all Nitrobacter species (Wagner et al., 1996)

- Ntspa712, specific for most members of the phylum Nitrospira (Daims et al., 2001)

- Ntspa662, specific for the genus Nitrospira (Daims et al., 2001).

Biofilm samples were hybridised with probe NON338 labelled with FLUOS and Cy3, to exclude non-specific probe binding (Manz et al., 1992). In none of the samples was non-specific labelling of cells observed. For visualisation of the different probe-targeted bacteria, simultaneous hybridisations were performed with Cy3-labelled specific probes and the FLUOS labelled bacterial probe set. Fluorescence signals were recorded with an LSM 510 confocal laser scanning microscope (Zeiss, Germany) equipped with a $\mathrm{HeNe}$ laser $(543 \mathrm{~nm})$ for detection of Cy3 and with an Argon laser (450-514 nm) for detection of FLUOS.

\subsection{Calculation procedures}

The ammonium supplied to the SBBR is removed by nitrification/denitrification and assimilation processes. The percentage of nitrification was calculated as the ratio between the amount of ammonium oxidised and the total amount of ammonium supplied to the reactor in each cycle:

$$
\% \text { Nitrification }=\frac{m_{\mathrm{removed}}^{N-N H_{+}^{+}}-m_{\text {assimilated }}^{N-N H_{+}^{+}}}{C_{A}^{N-N H_{4}^{+}} \cdot V_{A}} \cdot 100
$$

where $C_{A}^{N-N H_{4}^{+}}$refers to the concentration of ammonium in the feed and $V_{A}$ to the volume of feed supplied in each cycle. The amount of ammonium assimilated into biomass was calculated as:

$$
m_{\text {assimilated }}^{N-N H_{4}^{+}}=m_{\text {removed }}^{\text {acetate }} \cdot v_{N-N H_{4}^{+} / \text {acetate }}
$$

where $v_{N-N H_{+}^{+} / \text {actate }}$ is the stoichiometric yield relating biomass growth to acetate removal.

The percentage of denitrification was calculated as the ratio between the amount of $\mathrm{NO}_{x}$ removed and the total amount of ammonium supplied to the reactor in each cycle:

$$
\% \text { Denitrification }=\frac{m_{\mathrm{removed}}^{N-N H_{+}^{+}}-m_{\text {assimilated }}^{N-N H_{+}^{+}}-C_{D}^{N-N O_{x}} \cdot V_{D}}{C_{A}^{N-N H_{4}^{+}} \cdot V_{A}} \cdot 100
$$

where $C_{D}^{N-N O_{x}}$ refers to the concentration of nitrite plus nitrate in the effluent and $V_{D}$ to the volume discharged in each cycle.

The percentage of nitrogen removed by nitrification/denitrification and assimilation processes was calculated as the ratio between the amount of nitrogen removed by the total amount of ammonium supplied to the reactor in each cycle:

$$
\% N_{\text {removed }}=\frac{C_{A}^{N-N H_{4}^{+}} \cdot V_{A}-C_{D}^{N} \cdot V_{D}}{C_{A}^{N-N H_{4}^{+}} \cdot V_{A}} \cdot 100
$$


where $C_{D}^{N}$ is the total nitrogen concentration (ammonium plus nitrite plus nitrate) in the effluent.

The ratio between PHB and active biomass (without PHB) was calculated according to Beun et al. (2002) and can be expressed either as a mass ratio,

$$
\% \text { PHB }=\frac{\text { PHB }}{\mathrm{PHB}+X+\mathrm{ash}} \cdot 100
$$

where $X+a s h$ refers to the amount of active biomass, or as a carbon molar ratio,

$$
f_{\mathrm{PHB}}=\frac{\% \mathrm{PHB}}{100-\% \mathrm{PHB}} \cdot \frac{M W^{X+\text { ash }}}{M W^{\mathrm{PHB}}}
$$

where $M W^{X+a s h}$ and $M W^{\mathrm{PHB}}$ refers to the moleculer weight of the active biomass and polymer, respectively.

\section{Results and discussion}

The SBBR was at steady state before detailed measurements were made. The reaching of steady state was concluded from a constant biomass dry weight in the reactor as well as from reproducible nitrogen and carbon time profiles during consecutive cycles. At the selected hydraulic retention time, a combination of suspended and biofilm growth in the SBBR with predominance of the fixed form of biomass was observed. Table 2 summarises steady-state concentrations of ammonium, nitrite and nitrate in the effluent and biomass dry weight in the reactor.

Table 2 Concentrations of ammonium, nitrite, and nitrate in the effluent and biomass dry weight in the reactor at steady-state SBBR operation

\begin{tabular}{lcccccc}
\hline & Aerated & \multicolumn{2}{c}{ Biomass dry weight $(\mathrm{mg} / \mathrm{L})$} & \multicolumn{3}{c}{ Nitrogen concentration $(\mathrm{mg} / \mathrm{L})$} \\
\cline { 2 - 7 } Fill mode & Time $(\mathrm{min})$ & Biofilm & Suspension & $\mathrm{N}-\mathrm{NH}_{4}^{+}$ & $\mathrm{N}_{\mathrm{N} \mathrm{O}_{2}}^{-}$ & $\mathrm{N}-\mathrm{NO}_{3}^{-}$ \\
\hline Dump fill & 165 & 2968 & 450 & 0.30 & 0.35 & 7.81 \\
Slow fill & 140 & n.d. & 200 & 0.60 & 0.49 & 14.35 \\
Slow fill & 60 & 1956 & 250 & 2.48 & 1.00 & 10.91 \\
Slow fill & 50 & 2409 & 380 & 16.30 & 0.30 & $<2$ \\
Slow fill & 20 & n.d. & 300 & 18.70 & 0.12 & $<2$ \\
\hline
\end{tabular}

n.d: not determined.

\subsection{SBBR operation with dump fill}

Figure 3 shows profiles of nitrogen ions, acetate and oxygen, during a typical SBBR cycle with dump fill. During the mix fill phase, nitrate, left over from the previous cycle, was completely denitrified with acetate, without nitrite accumulation. Time profiles of ammonium, nitrite and nitrate concentration in the aerated phase showed the typical behaviour of nitrification reactions, via nitrite formation and subsequent oxidation to nitrate. 
Figure 3 Acetate $(\square)$, oxygen $(x)$, ammonium $(\bullet)$, nitrite $(\circ)$ and nitrate $(\mathbf{\Delta})$ profiles during a representative SBBR cycle with dump fill

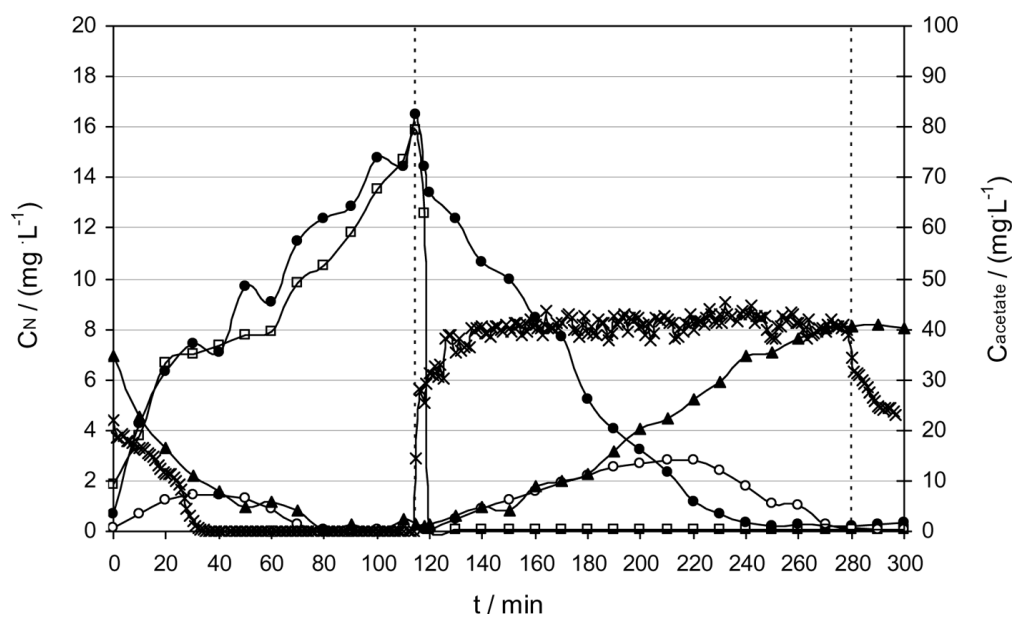

The microbial population in the SBBR with dump fill was subjected to alternating high/low acetate concentration in the liquid phase, known as 'feast-famine' conditions, over time. During the mixed fill phase, acetate was in excess in the liquid phase and a residual amount of PHB was measured in the biomass: PHB-biomass ratio $\left(f_{\mathrm{PHB}}\right)$ of suspended biomass and biofilm was $0.04 \mathrm{~mol} \cdot \mathrm{mol}^{-1}$ and $0.01 \mathrm{~mol} \cdot \mathrm{mol}^{-1}$, respectively. The discontinuation of feed addition and simultaneous oxygen supply (aerated phase) induced a fast decrease of acetate and an increase of $f_{\mathrm{PHB}}$, both in suspended biomass and in the biofilm. The maximum values of $f_{\mathrm{PHB}}$ measured were $0.12 \mathrm{~mol} \cdot \mathrm{mol}^{-1}$ for suspended biomass and $0.02 \mathrm{~mol} \cdot \mathrm{mol}^{-1}$ for the biofilm. After acetate depletion in the bulk liquid, PHB was degraded until in both kinds of biomass the initial value was reached again. These results indicate that the maximum $f_{\mathrm{PHB}}$ of suspended biomass was considerably higher than the one of biofilm. This may possibly be explained by a combination of two factors: lower mass transfer limitation of acetate and higher fraction of heterotrophs in suspended biomass when compared with the ones of biofilm. A significant amount of research has focused on the aerobic storage of acetate as PHB in activated sludge cultures and the reported maximum $f_{\mathrm{PHB}}$ values are in the range between $0.12 \mathrm{~mol} \cdot \mathrm{mol}^{-1}$ and $0.20 \mathrm{~mol} \cdot \mathrm{mol}^{-1}$ (Majone et al., 1999; Beun et al., 2000; Dircks et al., 2001; Carta et al., 2001). On the contrary, storage phenomena in biofilm systems are still poorly documented in literature. Beun et al. (2001) reported maximum $f_{\mathrm{PHB}}$ values for a biofilm in the range between $0.02 \mathrm{~mol} \cdot \mathrm{mol}^{-1}$ and $0.04 \mathrm{~mol} \cdot \mathrm{mol}^{-1}$ obtained in an airlift reactor with sequential operation. The results obtained in this study are in agreement with those reported in literature for suspended biomass and biofilm. The maximum poly-beta-hydroxyvalerate (PHV)-biomass ratio $\left(f_{\mathrm{PHV}}\right)$ measured both in suspended biomass and in the biofilm was one order of magnitude lower than the corresponding $f_{\mathrm{PHB}}$. This result is in agreement with those reported by Carucci et al. (2001) and Reis et al. (2003). Both authors found that PHB is the storage polymer synthesised in higher amounts when acetate is present as the sole carbon source.

The percentages of nitrification, denitrification and nitrogen removal in the SBBR with dump fill, determined as outlined in the materials and methods section, were $68.5 \%$, $48.1 \%$ and $75.7 \%$, respectively. The carbon stored as PHB was not used to denitrify the 
nitrate produced in the aerated phase, when acetate was at limiting concentration because the oxygen concentration in the bulk liquid was at saturation. Instead, PHB was probably used for biomass production and energy needs. Denitrification occurred mainly during the fill phase with acetate.

\subsection{SBBR operation with slow fill}

The effect of aeration time in the nitrification and denitrification processes was investigated in the SBBR operating with intermittent aeration and slow fill. Figure 4 shows profiles of nitrogen ions, acetate and oxygen, during a typical SBBR cycle with slow fill and a total aeration time of 60 min divided in alternating 6 min aerated periods and 22 min non-aerated periods. Acetate was not detected in the liquid phase during all cycles meaning that the rate of acetate uptake by the heterotrophic population was higher than the rate of acetate supplied to the SBBR. In this condition, heterotrophs were always limited by the carbon source. The oxygen concentration varied periodically increasing to the saturation value during the aerated periods and decreasing to zero during the non-aerated periods. Ammonium concentration decreased with concomitant increase of nitrate concentration during the aerated periods, while a decrease of nitrate concentration was observed during the non-aerated periods, corresponding to the nitrification and denitrification processes, respectively.

Figure 4 Oxygen $(\times)$, ammonium $(\bullet)$, nitrite $(\circ)$ and nitrate $(\boldsymbol{\Delta})$ profiles during a representative SBBR cycle with slow fill and total aeration time of $60 \mathrm{~min}$

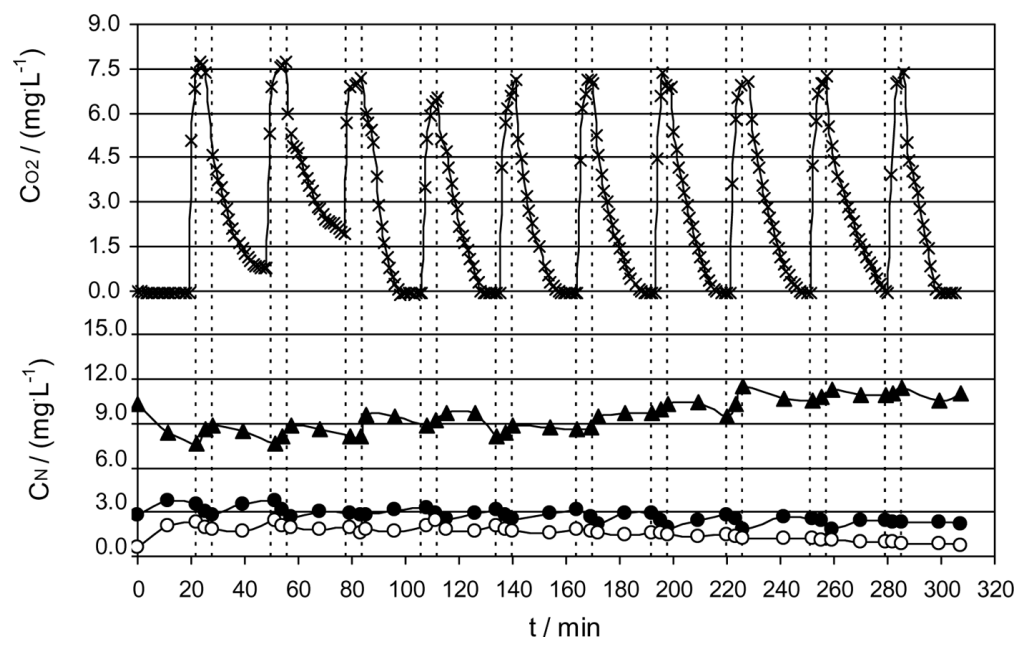

A residual amount of PHB was measured in the biomass during all cycle: PHB-biomass ratio $\left(f_{\mathrm{PHB}}\right)$ of suspended biomass was $0.015 \mathrm{~mol} \cdot \mathrm{mol}^{-1}$ and the one of biofilm was $0.004 \mathrm{~mol} \cdot \mathrm{mol}^{-1}$. The residual $f_{\mathrm{PHB}}$ of suspended biomass obtained in this study is of the same order of magnitude as the $f_{\mathrm{PHB}}$ of starved activated sludge biomass determined by Third et al. (2003), respectively, $0.008 \mathrm{~mol} / \mathrm{mol}$. The amount of PHV detected was not significant corresponding to the detection limit of the method used. As expected, accumulation of storage polymers was not observed, which can be explained by the continuous addition of acetate to the SBBR. 
The percentages of nitrification, denitrification and nitrogen removal in the SBBR with slow fill, determined as outlined in the Materials and Methods section, as a function of aeration time are depicted in Figure 5. The percentage of nitrification, corresponding to the ammonium oxidised to nitrate, increased continuously with aeration time, as expected. In contrast, both the percentage of denitrification, corresponding to the nitrate or nitrite reduced to molecular nitrogen, and the percentage of total nitrogen removed, by the combination of the nitrification and denitrification processes, presented a maximum value for an aeration time of $60 \mathrm{~min}$. Increasing further, the aeration time inhibited the denitrification processes despite the enhanced availability of nitrate. The percentages of nitrification, denitrification and nitrogen removal in the SBBR with slow fill operating with an optimum aeration time of $60 \mathrm{~min}$ per cycle, were $58.8 \%$, $39.0 \%$ and $69.2 \%$, respectively. These results are in agreement with those reported in literature regarding the utilisation of high frequency aeration (i.e., intermittent aeration) for nitrogen removal both in continuous and SBR systems. Zhao et al. (1999) reported that the denitrification percentage increased from $15 \%$ to $50 \%$ in a continuous system due to the implementation of a short-cycled aeration strategy. Also, Villaverde et al. (2000) implemented short-cycled aeration in an SBR reactor treating industrial wastewater with a high nitrogen load and obtained a nitrogen removal of $79 \%$.

Figure 5 Effect of the aeration time on the percentages of nitrification (white bars), denitrification (black bars) and nitrogen removal (stripe bars) in a SBBR

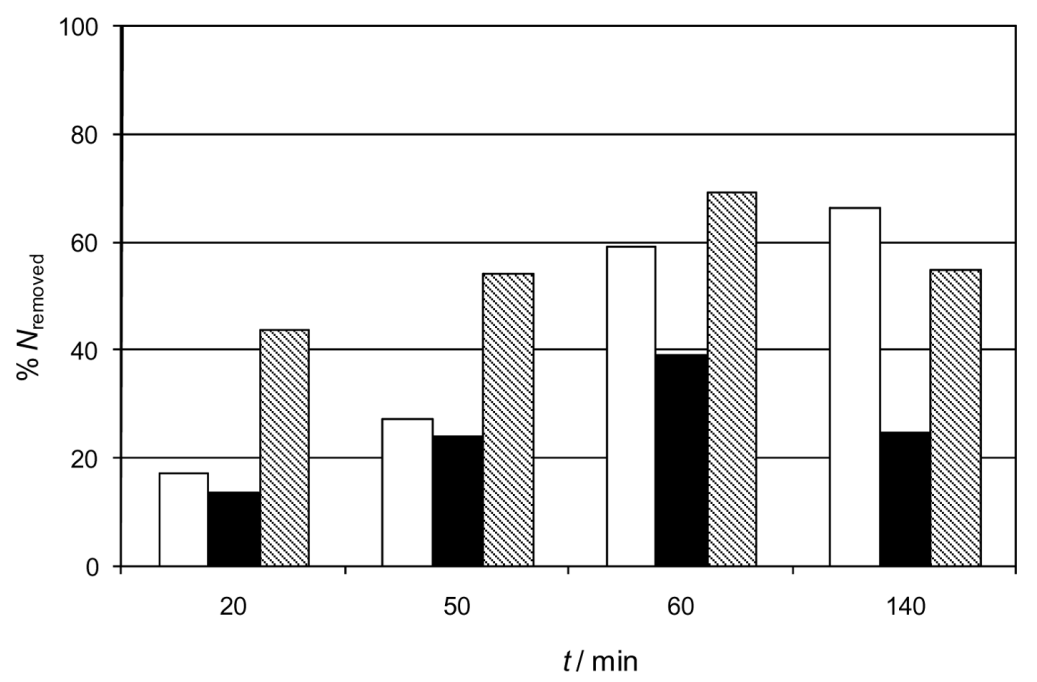

\subsection{Nitrifying microbial population composition in the biofilm and PHB-accumulating bacteria}

The nitrifying microbial populations in the biofilm were qualitatively evaluated using FISH with DNA oligonucleotide probes. The ammonia-oxidising cells in the biofilm samples could be labelled simultaneously with probes BET42a, Nso1225 and Nso190, which indicates that ammonia-oxidisers belong to the beta-subclass Proteobacteria. No hybridisation signal was observed with probe Nit3, whereas a bright signal was observed with the probe Ntspa662, which excludes the presence of bacteria belonging to the genus Nitrobacter. Thus, nitrite-oxidising cells in the biofilm were affiliated with the 
genus Nitrospira, which confirms the recent recognition of the importance of those bacteria for nitrite oxidation in several habitats (Daims et al., 2001; Nogueira et al., 2002; Nogueira and Melo, 2006). These results are valid for both operating strategies of the SBBR, namely dump fill and slow fill, with intermittent aeration. Only biofilm samples were analysed by FISH since the suspended biomass concentration was comparatively very low and dominated by heterotrophic bacteria (Table 2).

Inclusions of PHB in the biofilm and suspended biomass were only observed in samples collected in the SBBR operating with dump fill. This result indicates that PHB-accumulating heterotrophic bacteria are selected in the presence of alternating periods of abundance/deficiency of acetate, as previously reported in literature (Majone et al., 1999).

\subsection{Comparison between SBBR operating strategies for nitrogen removal}

The percentage of nitrogen removed in the SBBRs operating with distinct strategies, namely dump fill and slow fill, with optimum intermittent aeration was quite similar, $75.7 \%$ and $69.2 \%$, respectively. An important conclusion, which can be drawn from this study, is that intermittent aeration allowed a considerable energy saving without compromising significantly nitrogen removal.

The denitrification process could be further improved in the SBBR operating with dump fill. To utilise the carbon preserved as PHB to denitrify the nitrate produced in the aerated phase, it would be necessary to reduce the dissolved oxygen concentration in the liquid phase to favour the occurrence of simultaneous nitrification/denitrification.

\section{Conclusions}

A considerable energy saving regarding aeration was obtaining in the SBBR operating with slow fill with optimum intermittent aeration without compromising significantly nitrogen removal. In this context, it is predictable that most of the existing activated sludge wastewater treatment facilities, which are single continuous flow reactors, can be upgraded for simultaneous carbon and nitrogen removal in the same reactor using intermittent aeration.

\section{Acknowledgement}

This work was supported by Fundação para a Ciência e a Tecnologia and FEDER, Program POCI 2010 (POCI/AMB/61155/2004).

\section{References}

Andreottola, G., Foladori, P. and Ragazzi, M. (2001) 'On-line monitoring of a SBR system for nitrogen removal from industrial wastewater’, Wat. Sci., Tech., Vol. 43, No. 3, pp.93-100.

APHA (1995) Standard Methods for the Examination of Water and Wastewater, 19th ed., American Public Health Association, New York. 
Batistoni, P., Boccadoro, R., Bolzonella, D. and Marinelli, M. (2003) 'An alternate oxic-anoxic process automatically controlled. Theory and practice in a real treatment plant network', Wat. Sci. Tech., Vol. 48, Nos. 11-12, pp.337-344.

Beun, J.J., Dircks, K., van Loosdrecht, M.C.M. and Heijnen, J.J. (2002) 'Poly-beta-hydroxybuyrate metabolism in dynamically fed mixed microbial cultures', Wat. Res., Vol. 36, pp.1167-1180.

Beun, J.J., Heijnen, J.J. and van Loosdrecht, M.C.M. (2001) 'N-removal in a granular sequencing batch airlift reactor', Biotech. Bioeng., Vol. 75, No. 1, pp.82-92.

Beun, J.J., Paletta, F., van Loosdrecht, M.C.M. and Heijnen, J.J. (2000) 'Stoichiometry and kinetics of poly-beta-hydroxybutyrate metabolism in aerobic, slow growing, activated sludge cultures', Biotech. Bioeng., Vol. 67, No. 4, pp.379-388.

Brito, A.G., Peixoto, J., Oliveira, J.M., Oliveira, J.O., Costa, C., Nogueira, R. and Rodrigues, A. (2007) 'Brewery and winery wastewater treatment: some focal points of design and operation', in Oreopoulou, V. and Winfried, R. (Eds.): Utilization of By-Products and Treatment of Waste in the Food Industry, ISEKI-Food Book Series, Vol. 3, Springer, New York, pp.109-131.

Carta, F., Beun, J.J., van Loosdrecht, M.C.M. and Heijnen, J.J. (2001) 'Simultaneous storage and degradation of PHB and Glycogen in activated sludge cultures', Wat. Res., Vol. 35, No. 11, pp.2693-2701.

Carucci, A., Dionisi, D., Majone, M., Rolle, E. and Smurra, P. (2001) 'Aerobic storage by activated sludge on real wastewater', Wat. Res., Vol. 35, No. 16, pp.3833-3844.

Christensson, M. and Welander, T. (2004) 'Treatment of municipal wastewater in a hybrid process using a new suspended carrier with large surface area', Wat. Sci. Tech., Vol. 49, No. 11, pp.207-217.

Daims, H., Purkhold, U., Arnold, E., Wilderer, P.A. and Wagner, M. (2001) 'Nitrification in sequencing biofilm batch reactors: lessons from molecular approaches', Wat. Sci. Tech., Vol. 43, No. 3, pp.9-18.

Dircks, K., Henze, M., van Loosdrecht, M.C.M., Mosbaek, H. and Aspergren, H. (2001) 'Storage and degradation of poly-beta-hydroxybutyrate in activated sludge under aerobic conditions', Wat. Res., Vol. 35, No. 9, pp.2277-2285.

Foglar, L. and Briski, F. (2003) 'Wastewater denitrification process - the influence of methanol and kinetic analysis', Biochem. Proc., Vol. 39, No. 1, pp.95-103.

Kishida, N., Kim, J.H., Tsuneda, S., Sasaki, H. and Sudo, R. (2004) 'Automatic strategy for biological nitrogen removal of low $\mathrm{C} / \mathrm{N}$ wastewater in a sequencing batch reactor', Wat. Sci. Tech., Vol. 50, No. 10, pp.45-50.

Luostarinen, S., Luste, S., Valentin, L. and Rintala, J. (2006) 'Nitrogen removal from on-site treated anaerobic effluents using intermittently aerated moving bed biofilm reactors at low temperatures', Wat. Res., Vol. 40, pp.1607-1615.

Mace, S. and Mata-Alvarez, J. (2002) 'Utilization of SBR technology for wastewater treatment: an overview', Ind. Eng. Chem. Res., Vol. 41, pp.5539-5553.

Majone, M., Dircks, K. and Beun, J.J. (1999) 'Aerobic storage under dynamic conditions in activated sludge processes. The state of the art', Wat. Sci. Tech., Vol. 39, No. 1, pp.61-73.

Majone, M., Dircks, K. and Beun, J.J. (1999) 'Aerobic storage under dynamic conditions in activated sludge processes. The state of the art', Wat. Sci. Tech., Vol. 39, No. 1, pp.61-73.

Manz, W., Amman, R., Ludwig, W., Wagner, M. and Schleifer, K.H. (1992) 'Phylogenic oligonuclotide probes for the major subclasses of Proteobacteria: Problems and solutions', Syst. Appl. Microbiol., Vol. 15, pp.593-600.

Mobarry, B.K., Wagner, M., Urbain, V., Rittmann, B.E. and Stahl, D.A. (1996) 'Phylogenetic probes for analysing abundance and spatial organization of nitrifying bacteria', Appl. Env. Microbiol., Vol. 62, No. 6, pp.2156-2162.

Nicolella, C., van Loosdrecht, M.C.M. and Heijnen, J.J. (2000) 'Wastewater treatment with particulate biofilm reactors', J. Biotech, Vol. 80, pp.1-33. 
Nogueira, R. and Melo, L. (2006) 'Competition between Nitrospira spp. and Nitrobacter spp. in nitrite-oxidizing bioreactors', Biotech. Bioeng., Vol. 95, No. 1, pp.169-175.

Nogueira, R., Matos, M., Alves, C. and Brito, A.G. (2008) 'Synthesis and degradation of poly-beta-hydroxybutyrate in a sequencing batch biofilm reactor', Bioresource Technology, Vol. 100, pp.2106-2110.

Nogueira, R., Melo, L.F., Purkhold, U., Wuertz, S. and Wagner, M. (2002) 'Microbial population dynamics versus nitrification performance in biofilm reactors: effects of hydraulic retention time and the presence of organic carbon', Wat. Res., Vol. 36, No. 2, pp.469-481.

Puig, S., Vives, M.T., Corominas, L., Balaguer, M.D. and Colprim, J. (2004) 'Wastewater nitrogen removal in SBRs applying step-feed strategy: from lab-scale to pilot-plant operation', Wat. Sci. Tech., Vol. 50, No. 10, pp.89-86.

Qin, L. and Liu, Y. (2006) 'Aerobic granulation for organic carbon and nitrogen removal in alternating aerobic-anoxic sequencing batch reactor', Chemosphere, Vol. 63, pp.926-933.

Rees, G.N., Vasiliadis, G., May, J.W. and Bayly, R.C. (1992) 'Differentiation of polyphosphate and poly-beta-hydroxybutyrate granules in an Acinetobacter sp. isolated from activated sludge', FEMS Microbiol. Lett., Vol. 94, pp.171-176.

Reis, A.M.C., Serafim, L.S., Lemos, P.C. and Ramos, A.M. (2003) 'Production of polyhydroxyalkanoates (PHA) by mixed microbial cultures', Biopr. Biosyst. Eng., Vol. 25, pp.377-385.

Rodrigues, A.C., Brito, A.G. and Melo, L.F. (2001) 'Post-treatment of a brewery wastewater using a Sequencing Batch Reactor', Water Environment Research, Vol. 73, pp.45-51.

Smolders, G.J.F., van der Meij, J., van Loosdrecht, M.C.M. and Heijnen, J.J. (1994) 'Stoichiometric model of the aerobic metabolism of the biological phosphorus removal process', Biotech. Bioeng., Vol. 44, No. 7, pp.837-848.

Tam, H.L.S., Tang, D.T.W., Leung, W.Y. and Ho, K.M. (2004) 'Performance evaluation of hybrid and conventional sequencing batch reactor and continuous processes', Wat. Sci. Tech., Vol. 50, No. 10, pp.59-65.

Third, K.A., Burnett, N. and Cord-Ruwisch, R. (2003) 'Simultaneous nitrification and denitrification using stored substrate (PHB) as electron donor in an SBR', Biotech. Bioeng., Vol. 83, No. 6, pp.706-720.

Villaverde, S., Garcia, P.A., Lacalle, M.L. and Fdz-Polanco, F. (2000) 'New operational strategy for SBR technology for nitrogen removal from industrial wastewater highly loaded with nitrogen', Wat. Sci. Tech., Vol. 3, pp.171-183.

Vishniac, W. and Santer, M. (1957) 'The Thiobacilli', Bacteriological Reviews, Vol. 21, No. 3, pp.195-213.

Wagner, M., Rath, G., Koops, H.P., Flood, J. and Amann, R. (1996) 'In situ analysis of nitrifying bacteria in sewage treatment plants', Wat. Sci. Tech., Vol. 34, No. 1, pp.237-244.

Wilderer, P.A., Irvine, R.L. and Goronsky, M.C. (2001) Sequencing Batch Reactor Technology, IWA Scientific ans Technical Report No. 10, IWA Publishing, London UK.

Zhao, H.W., Mavinic, D.S., Oldham, W.K. and Koch, F.A. (1999) 'Controlling factors for simultaneous nitrification and denitrification in a two-stage intermittent aeration process treating domestic sewage', Wat. Res., Vol. 33, No. 4, pp.961-977. 